\title{
High voltage electrocution injury - A case report
}

\author{
Ashish Tyagi ${ }^{*}$, Shiv Shankar ${ }^{2}$, Hitesh Chawla ${ }^{3}$, Kapil Yadav $^{4}$, Hemant Kumar ${ }^{5}$ \\ ${ }^{\mathbf{1}}$ Assistant Professor, ${ }^{\mathbf{2}, \mathbf{4}}$ Post Graduate, ${ }^{\mathbf{3}}$ Associate Professor, Dept. of Forensic Medicine, Shaheed Hasan Khan Mewati Government \\ Medical College, Nalhar, Haryana, India
}

*Corresponding Author: Ashish Tyagi

Email: djashtag96@gmail.com

\begin{abstract}
High voltage electrical injuries are comparatively unusual but show a high rate of mortality. A dead body of a truck driver who died while his truck trapped in overhead high-voltage cables was brought for post-mortem examination. The autopsy revealed typical electrocution injuries with first and second-degree burns, peeled off epidermis and flash burns around the body at different areas. The severity of electric shock varies between simple harmless shock to death. The passage of electric current through the body produces wide range of effects, varying from insignificant localized spasm, little or no contact burns, fatality with little or no burns or extreme severe burning. This case report discusses the injuries sustained by a young adult drive while driving a truck, due to accidental contact of vehicle with overhead hightension wire.
\end{abstract}

Keywords: High-voltage electrocution, Accidental contact, Burns, Electrical injuries.

\section{Introduction}

Electric current is the movement or flow of electrically charged particles. The passage of a substantial electrical current through the tissue can cause skin lesions, organ damage and death. This injury is commonly called electrocution. Electric fatalities are usually accidental in nature. ${ }^{1}$ Electric injuries, a different type of mechanical trauma with a unique injury pattern occur due to lightning, low voltage (less than $600 \mathrm{~V}$ ) or high voltage (more than $600 \mathrm{~V})$ electrocution and most of the incidents are accidental and preventable. ${ }^{2}$ Though the word "electrocution" has derived from 'electro' and 'execution' it is usually used to address the accidental and suicidal circumstances as well though rarely. ${ }^{3}$ High voltage electrical injuries are relatively uncommon but, considerably contribute to occupational fatalities with the existence of hazardous exposure during their tasks at workplaces. ${ }^{4}$ They exhibit a high rate of mortality, and severe systemic complications those who are survived. One of main reason which contributes to maximum cases of electrical fatalities in accidental electrocution is carelessness or ignorance.

This case report discusses the injuries sustained by a male truck driver following an accidental contact of his vehicle while driving with a high voltage wire.

\section{Case Report}

A dead body of a 19-year-old male, driver by profession was brought for the postmortem examination to the mortuary of a tertiary care hospital. According to the investigating police officer the alleged incident happened while the victim was reversing back his truck which got in contact with a high-tension wire overhead. The alleged victim suffered high voltage shock and was declared dead at the scene of incident. The autopsy revealed following injuries which were observed during external examination:

An oval shape electrocution joule burn wound of size $2 \mathrm{~cm} \times 1 \mathrm{~cm}$ present over dorsum of left hand with the edges of the wound showed inverted margins and raised ridge of skin around whole of circumference with charring and peeling of epidermis over the hand. There was superficial to deep burns present over the surrounding tissues involving the dorsal surface of entire left hand (Fig. 1). On dissection floor of the wound was pale and there was no red line of demarcation.

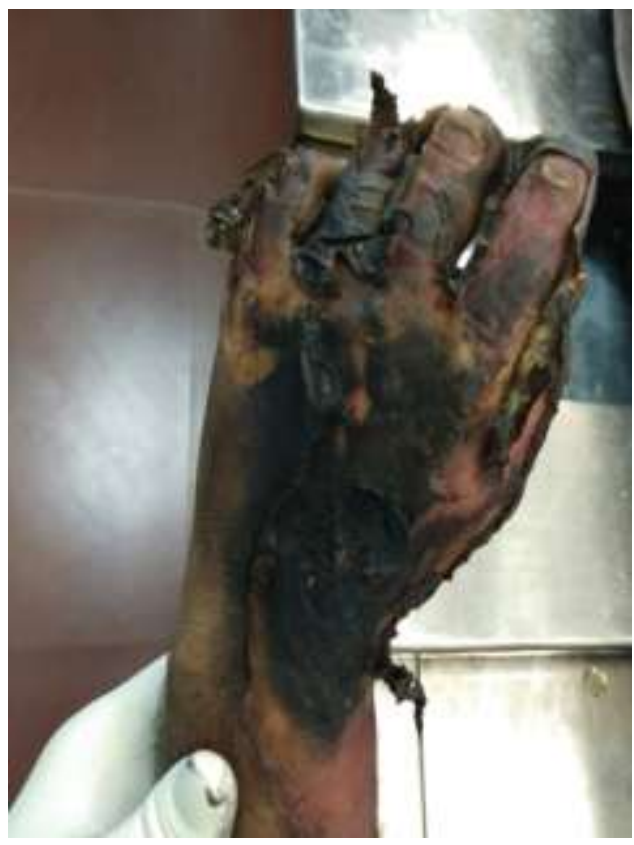

Fig. 1: Electrocution burn with peeled up epidermis

Another electrocution wound of size $1.5 \mathrm{~cm}$ x $1 \mathrm{~cm}$ subcutaneous deep present over posterior aspect of left elbow joint. The floor of the wound was smooth, hard in consistency and pale on dissection with raised firm edges. There was burnt parchmentised area around the wound extending from back of upper half of left arm till the upper half of dorsal region of left forearm along with singeing of hairs in the burnt area. (Fig. 2) 


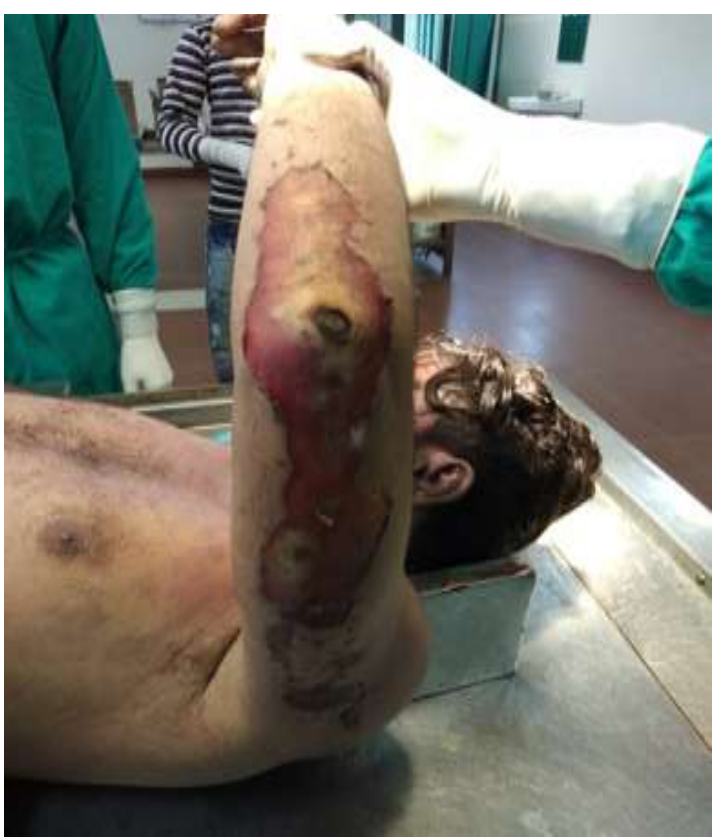

Fig. 2: Electrocution wound, and flash burns over left upper limb

There were multiple flash burns areas present anterior aspect of left side of abdominal wall (Fig. 3).They were superficial burns with peeled off epidermis and parchmentized undersurface. Singeing of hairs was appreciable.

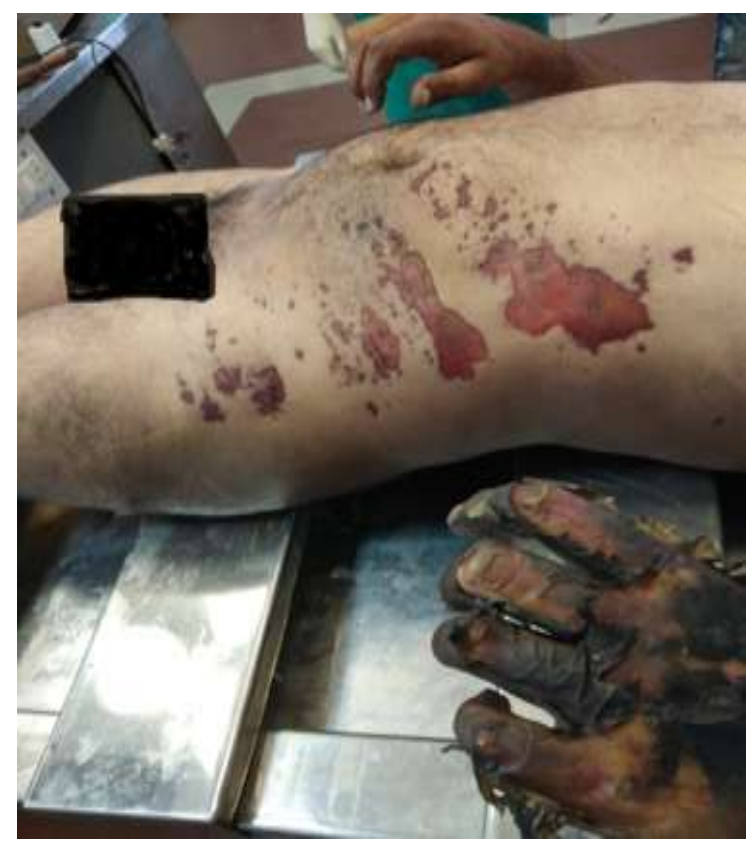

Fig. 3: Multiple flash burns over abdomen

There was also an oval shaped electrocution wound of size $1.5 \mathrm{~cm} \times 1 \mathrm{~cm}$ present over dorsal aspect of $3^{\text {rd }}$ toe on left foot with splitting of surrounding skin along with superficial to deep burns involving $3^{\text {rd }}, 4^{\text {th }}$ and $5^{\text {th }}$ toe with charring and peeling of epidermis (Fig. 4) Margins of wound were raised.

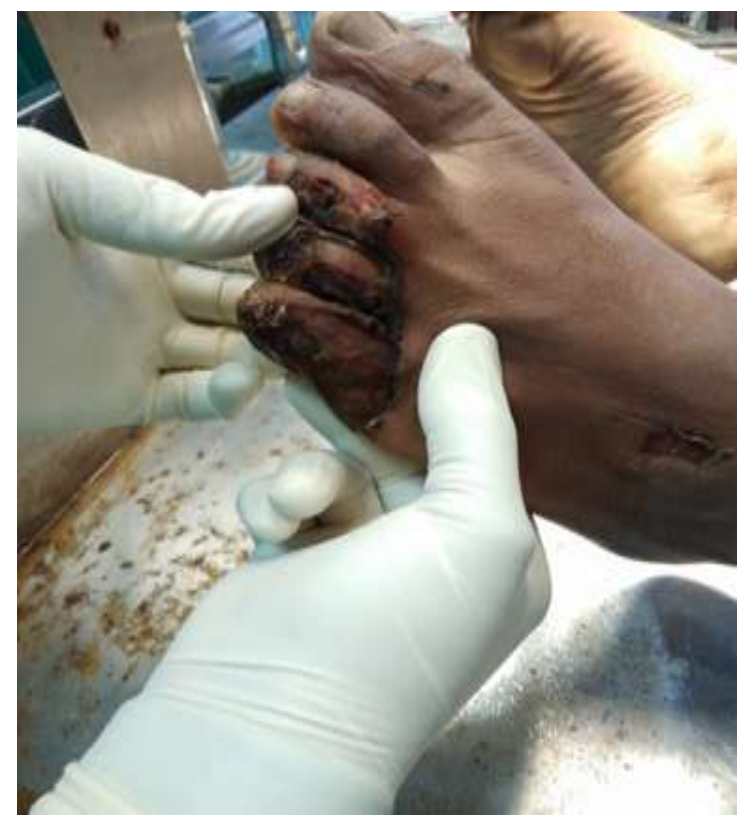

Fig. 4: Electrocution burns over left foot toes

Flash burnt parchmentized area was present over right great toe and $2^{\text {nd }}$ toe with peeled off epidermis.

All the visceral organs were congested and there was presence of showed subepicardial petechiael hemorrhages over heart. The brain was congested and edematous.

\section{Discussion}

The production of electrical injury depends on voltage, amount of current flow, the area of the contact and duration of contact. An electrical burn occurs only if the temperature of the skin is raised enough for a sufficiently long period to produce damage. The pathognomonic features of electrocution are the electric marks and joule burn when low or medium voltage current is involved. ${ }^{5}$ An arc produces considerably more burn than a contact that readily transmits the current and the greater the resistance offered by the individual tissue, the greater the damage. ${ }^{6}$ Though the incidence of high voltage electrocution is considerably low compared to the other types of electrical injuries, the fatality rate is very high with direct contact or indirect arcing or flashover effect.

In general, the tissue offers more resistance to electric current when it possesses less water content. For example, skin, bone, cartilage and hair are more resistant to the electricity than heart, brain or blood. Thus, examination by autopsy ordinarily reveals electrical burn mark on the skin rather than the internal organs. Thicker epidermal areas like those found on the back, haunch, palm and sole have a greater resistance while thin epidermal areas have a decreased resistance. Intact skin offers greater protection; after an electric injury, the resistance of charred skin drops to nearly zero, significantly reducing the protective effect of skin. ${ }^{7}$ Diagnosis of high voltage electrocution is sometimes difficult in the absence of history and circumstantial evidence, as the pathognomic features like electric marks and joule burns are often seen only with low or medium 
voltage current involvement and also both entry and exit marks are seen together only in $20 \%$ of cases. ${ }^{8}$

There is added type of electric mark called as spark burn which occurs with the presence of a gap between the skin and the conductor. In high voltage electrocution, multiple spark burns blow out into the victim causes a large areas of tissue damage. There were 1 st and 2 nd degree burns also with flash effect over the back of the body and singeing of hairs due to the short-range flashes. Intra-epidermal separation and sub-epidermal separation are common in electrical lesions. Tissue fluid evaporation caused by heat results in the separation of epidermal cells. ${ }^{1}$

In high-voltage accidents, direct contact with the wire is not necessary. As the body approaches the high voltage line, an electric current (arc) may jump from the line to the body. Death from high-voltage electrocution is usually caused by either the electro thermal injury produced by the current, or respiratory arrest. The temperature generated by an arc current can be as high as $40,000^{\circ} \mathrm{C}$. In urban areas, the usual high-voltage line carries $7000-8000 \mathrm{~V}$, line to ground. Electrocution from these lines occurs when they break, fall to the ground and are touched, or when an intact or "live" line is touched by a tall metal object such as a ladder, pole, or crane with which a person is in contact. In contrast to low-voltage burns, high-voltage burns may be extremely severe, with charring of the body. If the burns occur from contact or proximity to a high-voltage line, numerous individual and confluent areas of third-degree burns will present. If the contact with the high-voltage current is not direct, but through current running through an intermediary object such as a ladder or pole, the burns are large and irregular, chalky white in color, often with raised borders and a central crater with yellowish or black discoloration of the burn sites caused by heat. ${ }^{9}$

The present case report refers to a truck driver who was accidentally got electrocuted with a high-tensionwire and discusses the injury pattern and gross consequences of tissues following high voltage electrocution. Poor maintenance of the electric cables along with usage of bad quality wire, breakage, which may remain unattended on the roadside may be the cause of accidental electrocution outdoors. According to the circumstantial evidence, the deceased truck had been contacted with the high voltage power lines while he was reversing it, resulting in the prolong contact which lead the electric mark at the contacted site (entry mark) to be unrecognizable. Multiple electrical marks were identified during the autopsy of the victim, and they were found all over the body.

\section{Conclusion and Recommendation}

The incidence of high voltage electrocution is somewhat infrequent than other electrical injuries according to several studies done in several countries. A detailed history regarding the incident, scene visit and proper postmortem examination with the histological analysis is recommended prior to concluding the cause of death as high voltage electrocution. The risk of getting electrocuted from the haphazardly installed electric wires without proper maintenance in most parts of this place is indeed a matter of concern. This case report also signifies the relevance of underground electric cables or proper insulation of overhead electric wires.

\section{Conflict of Interest: None.}

\section{References}

1. Saukko P, Knight B. Knight's Forensic pathology. $3^{\text {rd }}$ ed. London: Arnold. 2004; pp. 326,319-31.

2. Gupta BD, Mehta RA, Trangadia MM. Profile of deaths due to electrocution: A retrospective study. J Indian Acad Forensic Med 2012;34(1):13-5.

3. Wick R, Gilbert JD, Simpson E, Byard RW. Fatal electrocution in adults - a 30-year study. Med Sci law 2006;46(2):166-72.

4. Kisner S, Casini V. Epidemiology of electrocution fatalities: 1998. In: Worker deaths by electrocution: A summary of NIOSH Surveillance and Investigative Findings. Washington, DC, Department of Health and Human Services (NIOSH), Publication No. 98-131:9-19.

5. Polson D J, Gee D J \& Knight B: The essentials of Forensic Medicine, $4^{\text {th }}$ ed. Pergamon Press, Oxford, 1985.

6. Robinson DW, Masters FW, Forrest WJ. Electrical burns: A review and analysis of 33 cases, Surg 1965;57(3):385-90.

7. Abrante M, Cohen IL, Lumb PD. Cardiovascular problems in the post-operative trauma patient. In: Grande CM (ed). Textbook of Trauma, Anesthesia and Critical Care, St. Louis: Mosby; 1993:773-7.

8. Kumar SS, Narayan AR, Gopal S, Kumar JG, Agrawal A. High voltage electrical shock with multiple life-threatening injuries. Int J Critical Illness Injury Sci 2015;5(4):266.

9. DiMaio V, DiMaio D. Forensic medicine and pathology. $2^{\text {nd }}$ ed. USA: CRC press; 2001:245-9, 276.

How to cite this article: Tyagi A, Shankar S, Chawla H, Yadav K, Kumar H. High voltage electrocution injury - A case report. Int J Forensic Med Toxicol Sci 2019;4(2):68-70. 